\title{
Operando reactor-cell with simultaneous transmission FTIR \& Raman characterization (IRRaman) for the extended study of gas-phase reactions with solid catalysts
}

\author{
J. J. Ternero-Hidalgo', M.O. Guerrero-Pérez ${ }^{1 *}$, J. Rodríguez-Mirasol'1, T. \\ Cordero $^{1}$, M. A. Bañares ${ }^{2}$, R. Portela ${ }^{2}$, P. Bazin ${ }^{3}$, G. Clet ${ }^{3}$, M. Daturi3 ${ }^{*}$ \\ 1 Universidad de Málaga, Departamento de Ingeniería Química, E29071 \\ Málaga, Spain \\ ${ }^{2}$ Instituto de Catálisis y Petroleoquímica, CSIC, E28049 Madrid, Spain \\ ${ }^{3}$ Normandie Univ, ENSICAEN, UNICAEN, CNRS, LCS, 14000 Caen, France
}

KEYWORDS: operando; IR; Raman; heterogeneous catalysis; $\mathrm{VO}_{x} / \mathrm{ZrO}_{2}$; propane $\mathrm{ODH}$.

\section{ABSTRACT}

Raman and transmission FTIR spectroscopic techniques have been coupled in a new homemade reactor-cell designed in a joint CSIC-UNICAEN collaboration. The set-up is easily adapted to any FTIR and fibre-coupled Raman spectrometers and gas analysis techniques. Simultaneous operando FTIR and Raman spectroscopic measurement allow complementary characterization of adsorbed species, reaction intermediates, and structural properties of the catalyst. This system was validated with the study of vanadium based catalysts during propane OxyDeHydrogenation (ODH). The combined use of both spectroscopies with gas analysis techniques to measure the activity contributes to the understanding of propane ODH and the identification of the role of different oxygen species bound to vanadium sites. For example, the simultaneous characterization of the catalyst under the same conditions by IR and Raman confirms that the $V=O$ mode has the same frequency in both spectroscopies, and that bridging oxygen sites ( $\mathrm{V}-\mathrm{O}$ $\mathrm{V}, \mathrm{V}-\mathrm{O}-\mathrm{Zr}$ ) present higher activity than terminal $\mathrm{V}=\mathrm{O}$ bonds. These results demonstrate the high potential of the new simultaneous transmission IR-Raman operando rig to correlate the activity and the structure of catalysts, thus assisting the rational design of catalytic processes. 


\section{Introduction}

The establishment of relationships between surface structure and performance of catalysts is indispensable to understand catalytic reaction mechanisms and deactivation phenomena, identify active phases, and rationally design more efficient catalytic materials and processes. In this sense, there has been an increasing interest in the development of characterization techniques of functional materials under real operating conditions. In situ and operando characterization has been performed with different techniques, such as IR ${ }^{2-4,13-}$ 17, EPR ${ }^{18-19}$, synchrotron based techniques ${ }^{5,20-21}$, Raman ${ }^{6-8,22-30}$, NMR $^{9,10}$, UVVIS ${ }^{11}$ or TEM ${ }^{1,12}$. All these works point out the high-value information obtained by simultaneously tracking catalysts structure and reactivity, and the need for more technological progress, for example in the design of high quality reactioncells, the development of techniques for the study of interfaces, space and timeresolved spectroscopy, and, particularly, multimodal operando set-ups. Since each characterization technique can provide only a part of the picture, one of the present challenges is to combine different spectroscopic techniques in a single rig that provide complementary insights into catalysts behavior.

Several works report the use of different simultaneous characterization techniques to study the catalytic material and/or the reaction medium. Among these multimodal operando approaches, Baiker et al. ${ }^{31}$ performed a combined liquid-phase ATR-IR and XAS study during the aerobic oxidation of benzyl alcohol

over Pd based catalysts. They obtained information about the particle structure/oxidation state by XAS and the surface species by ATR-IR, and 
monitored the catalytic activity using FTIR spectroscopy. Weckhuysen's group ${ }^{32}$ designed a laboratory setup for combined operando X-ray diffraction and Raman spectroscopy of catalysts, with analysis of reaction products by gas chromatography. They used such setup to study the long-term deactivation of Co-based catalysts during Fischer-Tropsch synthesis. The same group also used XAFS, Raman and UV-Vis spectroscopies in a single experiment ${ }^{33}$. The combination of XAS, XRD and Raman for phase speciation in water gas shift reaction catalysts has also been performed ${ }^{34}$. The operando coupling of EPR, Raman and UV-Vis spectroscopies was reported by Bruckner ${ }^{35}$. These and other examples, as those highlighted in a review by Bentrup ${ }^{36}$, demonstrate how the coupling of complementary operando techniques in one rig results in more rational and comprehensive information, necessary for the efficient design of catalytic materials.

The combination of Raman and infrared spectroscopies is particularly convenient for supported oxides ${ }^{37}$, since Raman spectroscopy reports essentially the structure of the supported phase while IR has more sensitivity to adsorbed species. Payen et al. ${ }^{38}$ performed alternate in situ characterization by Raman and IR of Pd based catalysts for DeNOx using a commercial Raman spectrometer with an IR extension (Horiba Jobin Yvon). Zhang et al. ${ }^{39-40}$ designed a homemade high-throughput reactor that combines FTIR and Raman spectroscopies. That setup has six parallel reaction channels with six Raman probes tostudy the catalysts, while the gas product is analysed by FTIR imaging. Urakawa ${ }^{41}$ designed a DRIFTS-Raman setup configuration that enables simultaneous IRRaman detection with high spatial resolution in order to monitor the surface of catalysts during $\mathrm{NO}_{x}$ storage and reduction. These contributions underline the 
complementarity of both spectroscopies. It should be noted, though, that the measurements are not always simultaneous, and, in many cases, IR data rely on the use of DRIFTS or ATR-IR, two precious techniques which, however, are not directly quantitative and usually have lower sensitivity than transmission, since the scattered signal can be weak, and thus more difficult to interpret. Quantitative data are nevertheless required to elucidate the catalyst role for many reactions and to properly perform spectrokinetic studies ${ }^{42}$.

Thus, the present paper reports the design and validation of a novel concept of operando IR-Raman cell (the "IRRaman" operando reactor), conceived to obtain under real operating conditions, in a single experiment, with space and time consistency, transmission FTIR and Raman spectra of catalysts, coupled with online analysis of the reaction products. Therefore, information about the catalyst structure (mainly from Raman), adsorbed species (mainly from FTIR) and reactivity (from gas phase analysis) blend into a single experiment. The usefulness of this multimodal operando rig is demonstrated here though the study of the propane oxidative dehydrogenation $(\mathrm{ODH})$ reaction over $\mathrm{V}-\mathrm{Zr}-\mathrm{O}$ catalysts. Propane ODH has been largely studied ${ }^{43-47}$. Dispersed vanadia or molybdenabased catalysts are well known as active catalytic materials for this process. ${ }^{45}$ The reaction mechanism shows that surface monomeric and polymeric species are active and participate in the formation of propyl or (iso)propoxy species as first reaction intermediates, which are usually further oxidized giving rise to $\mathrm{CO}_{x}$ in the gas phase ${ }^{43}$. The evolution of the solid catalyst during the pre-activation treatment and, afterwards, under the reaction flow is followed here with the new IRRaman operando reactor and correlated to the development of the adsorbed species. 


\section{Experimental section}

Catalysts synthesis. Zirconium (IV) propoxide solution (Sigma-Aldrich, CAS: 23519-77-9, 70 wt. \% in 1-propanol), polyvinylpyrrolidone (PVP) (Sigma-Aldrich, CAS: 9003-39-8, Mw 1,300,000), acetylacetone (Sigma-Aldrich, CAS: 123-546, $\geq 99 \%$ ), 1-propanol (Sigma-Aldrich, CAS: $71-23-8, \geq 99.5 \%$ ) and vanadyl acetylacetonate (Sigma-Aldrich, CAS: $3153-26-2$, $\geq 97.0 \%$ ) were used as starting materials. The catalysts were prepared by electrospinning. The synthesis of the solutions has previously been described ${ }^{48}$. Briefly, the starting polymer solution was prepared by dissolving $2.100 \mathrm{~g}$ of the zirconium fibers precursor (zirconium (IV) propoxide) and $0.317 \mathrm{~g}$ of PVP in $2.984 \mathrm{~g}$ of 1-propanol solventwith $0.450 \mathrm{~g}$ of acetylacetone. Then, vanadyl acetylacetonate was added to three fractions of this polymer solution to obtain final fibers with nominal vanadium mass concentrations of $2.5 \%$ (Zr-V2.5), $5.0 \%$ (Zr-V5.0) and $6.4 \%$ (Zr-V6.4). Subsequently, the three polymer solutions were vigorously stirred for $24 \mathrm{~h}$ at room temperature. The electrospinning equipment and procedure have also been described in previous articles ${ }^{48-49}$. The electrospun fibers were calcined in air flow (150 $\left.\mathrm{mL} \cdot \mathrm{min}^{-1} \mathrm{STP}\right)$ at $500{ }^{\circ} \mathrm{C}$ in a conventional tubular furnace, with a heating rate of $10 \stackrel{\circ}{ } \mathrm{C} \cdot \mathrm{min}^{-1}$ followed by $6 \mathrm{~h}$ dwell time in order to eliminate the organic part and the remaining solvent, and to stabilize the zirconia fibers. The final vanadium mass concentration obtained by XPS analysis of Zr-V2.5, Zr-V5.0 and Zr-V6.4 samples was reported to be $2.7,4.9$ and $6.0 \%$, respectively ${ }^{48-49}$.

The "IRRaman" reactor. The IR-Raman operando rig was specifically designed at Laboratoire Catalyse et Spectrochimie (Caen, France), adapting a home-made 
operando IR reactor-cell for self-supported wafers of $\sim 20-30 \mathrm{mg}$ and $2 \mathrm{~cm}^{2}$ (the so-called "Sandwich" reactor) ${ }^{50}$ to also host a Raman probe (Figure 1). This cell is a genuine catalytic reactor, both from the point of view of fluid dynamics ${ }^{51}$ and catalyst morphology preservation ${ }^{52}$. Evolutions of the "Sandwich" cell have already been developed in the past to facilitate kinetic analysis ${ }^{51}$ or to determine reaction mechanisms in photocatalysis ${ }^{53}$. The adaptations made in the framework of this study (detailed in the SI) aim to continuously collect both transmission FTIR and backscattering Raman spectra from representative, closeby points of the pellet. Therefore, the cell was notably modified by replacing the two $\mathrm{KBr}$ windows positioned on one side of the cell by a stainless steel cylinder. Two holes were drilled in the cylinder, one to accommodate the Raman probe and another one for a dedicated small $\mathrm{KBr}$ window $(\mathrm{d}=4 \mathrm{~mm})$ to let the IR beam pass through. Air tightness was guaranteed via Kalrez O-rings. The position of the Raman probe, and thus the distance to the pellet surface (approximately 1 $\mathrm{mm}$ ), is adjustable to optimize the signal intensity. The pellet temperature is measured via a thermocouple placed on the sample holder to ensure proper temperature control independently of the new reactor configuration..

The cell is placed in an IR spectrometer bench (Nicolet 6700 FT-IR spectrometer equipped with a MCT/A detector) to record transmission IR spectra (64 scans/spectrum, $2 \mathrm{~cm}^{-1}$ resolution). A laser (532 $\mathrm{nm}$ ) beam generated by a Horiba Jobin Yvon Labram300 spectrometer is guided into the IRRaman reactor by an optical fiber and focused on the sample with an ad hoc InPhotonics Raman probe specially designed to withstand high temperatures. Raman spectra resolution was $1.5 \mathrm{~cm}^{-1}$ and laser power on the sample was $5 \mathrm{~mW}$. It must be noted that at the end of the experiments the pellet did not show any sign of local overheating 
or preferential carbon deposit in the analysis zone of the Raman laser. The dual IR-Raman operando reactor was fed with controlled gas flow rate and composition, and heated for catalyst activation or reaction. Downstream the catalyst wafer, the exhaust gases are directed towards an IR gas cell, and a mass spectrometer (MS) for simultaneous on line analysis.

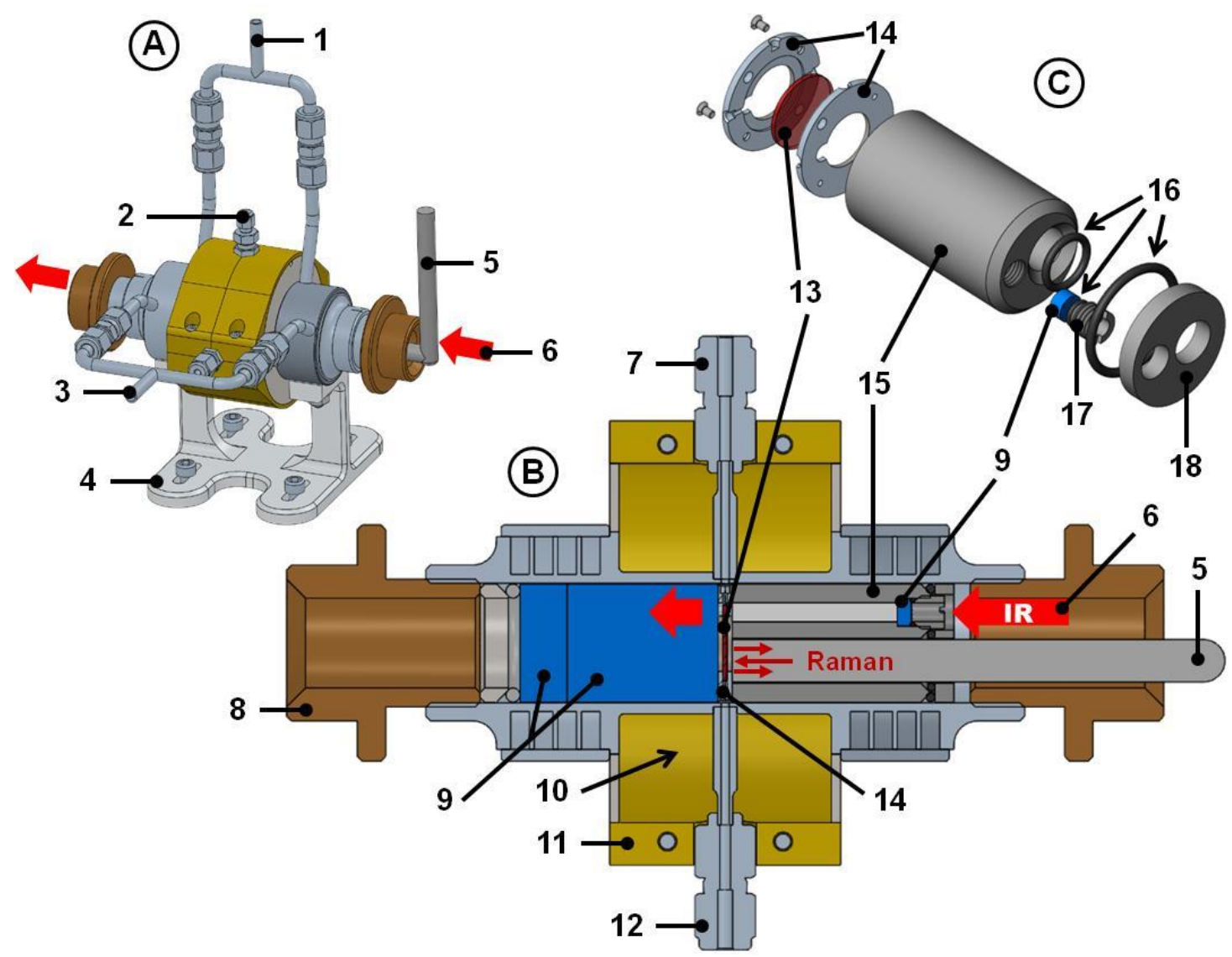

Figure 1. Description of the IRRaman device: $(A)$ general view in perspective, (B) longitudinal view, and (C) exploded view of the IRRaman accessory. (1) air cooling outlet, (2) thermocouple location, (3) air cooling inlet, (4) IRRaman cell support, (5) Raman probe, (6) IR beam, (7) gas outlet, (8) adjusting nut for airtightness, (9) $\mathrm{KBr}$ windows, (10) oven location, (11) external shell, (12) gas inlet, (13) sample (wafer), (14) wafer holder, (15) barrel of the IRRaman accessory, (16) Kalrez O-ring, (17) hollow clamping nut (for the passage of the IR beam), (18) cap of the IRRaman accessory.

ODH reaction conditions. Three catalytic materials (Zr-V2.5, Zr-V5.0 and ZrV6.4) were pressed into self-supported wafers and tested for ODH in the 
IRRaman operando reactor. The weight of catalyst $\left(\mathrm{W}_{\text {cat }}\right)$ and the total volumetric gas flow $\left(\mathrm{F}_{\mathrm{T}}\right)$ were $31.5 \mathrm{mg}$ and $18.1 \mathrm{~mL} \cdot \mathrm{min}^{-1}$, respectively, resulting in a spacetime $\left(\mathrm{W}_{\mathrm{cat}} / \mathrm{F}_{\mathrm{C} 3 \mathrm{H} 8}\right)$ of $0.53 \mathrm{gcat} \cdot \mathrm{s} \cdot \mathrm{mL}^{-1} \mathrm{C}$ СН8. The reaction temperature was varied from 200 to $340^{\circ} \mathrm{C}$. Two different gas mixtures were used in the $\mathrm{ODH}$ experiments, an activation flow of $10 \%$ oxygen in argon, and a reaction flow consisting of a mixture of $20 \%$ propane and $10 \%$ oxygen in argon. Dehydrogenation $(\mathrm{DH})$ experiments were also carried out without oxygen in the activation and reaction flows. Gas lines were heated at $60^{\circ} \mathrm{C}$ before and after the reaction-cell to pre-heat the reaction mixture and to avoid products condensation. The samples were first dehydrated by heat treatment under activation flow from room temperature to $340^{\circ} \mathrm{C}$ with a heating rate of $5^{\circ} \mathrm{C} \cdot \mathrm{min}^{-1}$. After dehydration and equilibration at the selected reaction temperature, the samples were submitted to activation and reaction flows with and without oxygen in different order. The conditions were changed when the steady state was achieved.

Operando FTIR and operando Raman spectra of the catalysts were acquired every 2 and $4 \mathrm{~min}$, respectively. Reactants and products of the gas phase were analyzed online by FTIR gas cell (one spectrum every $2 \mathrm{~min}$ ), and mass spectrometry (one measurement every $3 \mathrm{~s}$ ). These data provided conversion, selectivity, and TOF results, as detailed in the SI.

\section{Results and Discussion}

\section{1) Monitoring of the pre-activation of the catalysts}

Before reaction, the catalysts were dehydrated during the initial activation step. Figure 2 shows the simultaneous Raman and infrared spectra of the hydrated and dehydrated samples. The IRRaman approach allows the determination of all 
the vibrational bands from $5000 \mathrm{~cm}^{-1}$ to $150 \mathrm{~cm}^{-1}$, without the restrictions usually observed in IR spectroscopy of solids, where lattice bands absorb all the signal below ca. $1000 \mathrm{~cm}^{-1}$. All samples show broad Raman bands (642, 459, 314 and $268 \mathrm{~cm}^{-1}$ ) associated with the tetragonal phase of zirconia ${ }^{48,54}$, in agreement with the XRD results (Supporting Information, Figure S1); these bands are not sensitive to hydration/dehydration (Figure 2B) and are used to normalize the intensity of the Raman spectra. The infrared bands near $1630 \mathrm{~cm}^{-1}$ and at $3500-$ $3400 \mathrm{~cm}^{-1}$ show the presence of adsorbed water in all samples at room temperature (Figure 2A); these bands are respectively attributed to the $\mathrm{H}-\mathrm{O}-\mathrm{H}$ bending and $\mathrm{v}(\mathrm{OH})$ stretching modes ${ }^{55-56}$. The infrared signal of adsorbed water molecules increases with vanadia content and disappears upon dehydration (Figure 2A). Weak bands due to the hydroxyls on the solid are then visible around $3700 \mathrm{~cm}^{-1}$. The Raman and infrared $\mathrm{V}=\mathrm{O}$ modes near $1020 \mathrm{~cm}^{-1}$ 57-58; are characteristic of molecularly dispersed vanadium oxide species ${ }^{59}$ and blue-shift upon dehydration. Moreover, in dehydrated samples they blue-shift from 1019 to $1029 \mathrm{~cm}^{-1}$ as the vanadium content increases from 2.5 to $6.4 \%(\mathrm{w} / \mathrm{w})$, due to a higher relative population of polyvanadates with respect to monovonadates ${ }^{59}$. It is important to underline the highly consistent wavenumbers observed for the $V=O$ mode in both the Raman and the infrared spectra for all vanadia loadings (Figure 3). This implies that the cell design and the neighboring spots of analysis for IR and Raman are well-suited for the measurements in exactly the same conditions.

No additional information may be extracted from infrared spectra below $900 \mathrm{~cm}^{-}$ 1, due to the strong absorption of zirconia support. Conversely, Raman spectroscopy does provide additional information of vanadia species in that 
spectral window: the broad Raman signal in the $700-950 \mathrm{~cm}^{-1}$ range grows stronger with vanadium content and corresponds to $\mathrm{V}-\mathrm{O}-\mathrm{V}$ and $\mathrm{V}-\mathrm{O}-\mathrm{Zr}$ modes ${ }^{48,60}$, the signal for $\mathrm{V}-\mathrm{O}-\mathrm{V}$ chains appears near $880 \mathrm{~cm}^{-1}{ }^{61}$, while the broad signal near $770 \mathrm{~cm}^{-1}$ is assigned to $\mathrm{V}-\mathrm{O}-\mathrm{Zr}$ vibrations like in $\mathrm{ZrV}_{2} \mathrm{O}_{7}$ samples ${ }^{48,62}$. Since crystalline $\mathrm{V}_{2} \mathrm{O}_{5}$ presents intense Raman bands near 143 and $994 \mathrm{~cm}^{-1} 61$, its presence can be excluded in these samples. Infrared spectra provide additional complementary information. The infrared bands near 1580, 1456 and a shoulder near $1380 \mathrm{~cm}^{-1}$ present in the dehydrated samples are attributed to carbonaceous deposits. In particular, the band at $1580 \mathrm{~cm}^{-1}$ is characteristic of $\mathrm{C}=\mathrm{C}$ bond stretching in polycyclic aromatic compounds, while the weaker bands near 1456 and $1380 \mathrm{~cm}^{-1}$ have been attributed to the bending modes of $-\mathrm{CH},-\mathrm{CH}_{2}$ and $\mathrm{CH}_{3}$ species in carbonaceous deposits ${ }^{63-64}$. The presence of bidentate carbonates (weak features at about 1550, 1315 and $1060 \mathrm{~cm}^{-1}$ ) ${ }^{65}$ cannot be excluded either. The sharp band near $2339 \mathrm{~cm}^{-1}$ is associated with occluded $\mathrm{CO}_{2}$ ${ }^{66-67}$ that could be retained in the material closed porosity. This $\mathrm{CO}_{2}$ may originate fromthe calcination of the carbonaceous precursors. 


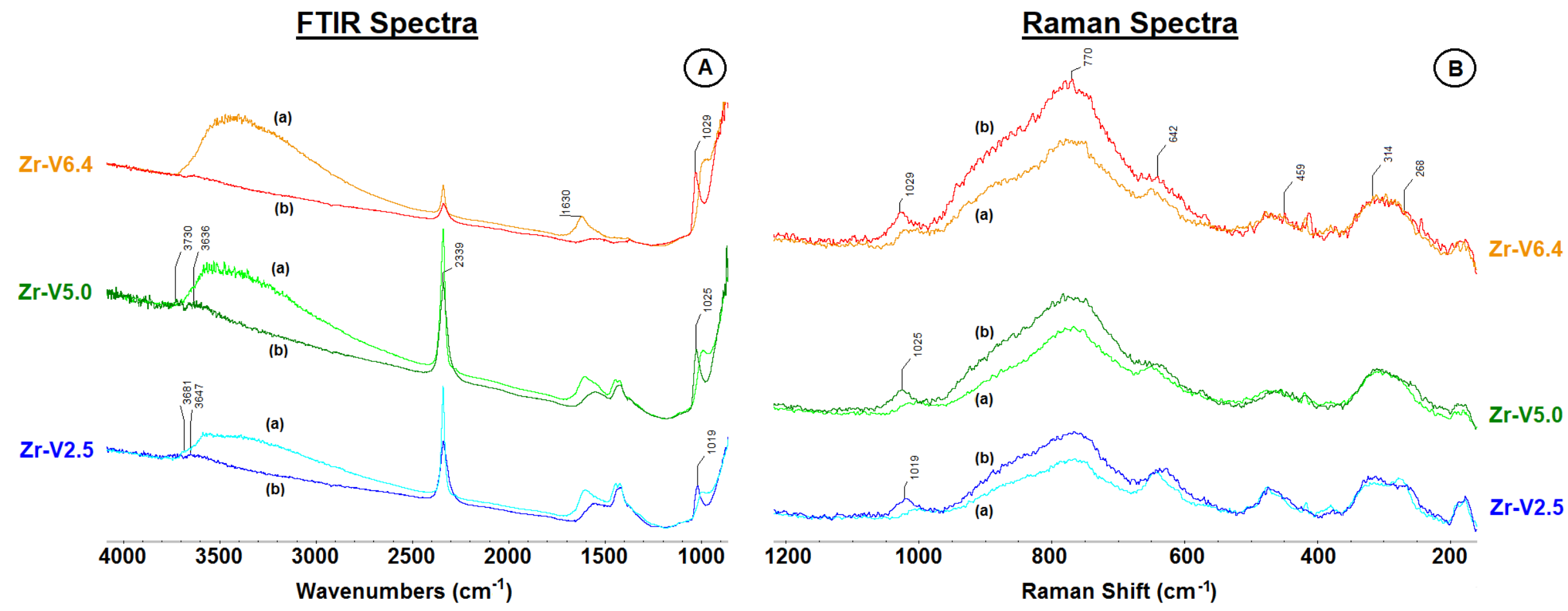

Figure 2. FTIR (A-left) and Raman (B-right) spectra obtained in the IRRaman reactor during dehydration under activation flow (10\% $\mathrm{O}_{2}$ in $\mathrm{Ar}$ ) at room temperature (a) and at the final temperature of $340^{\circ} \mathrm{C}(\mathrm{b})$. 


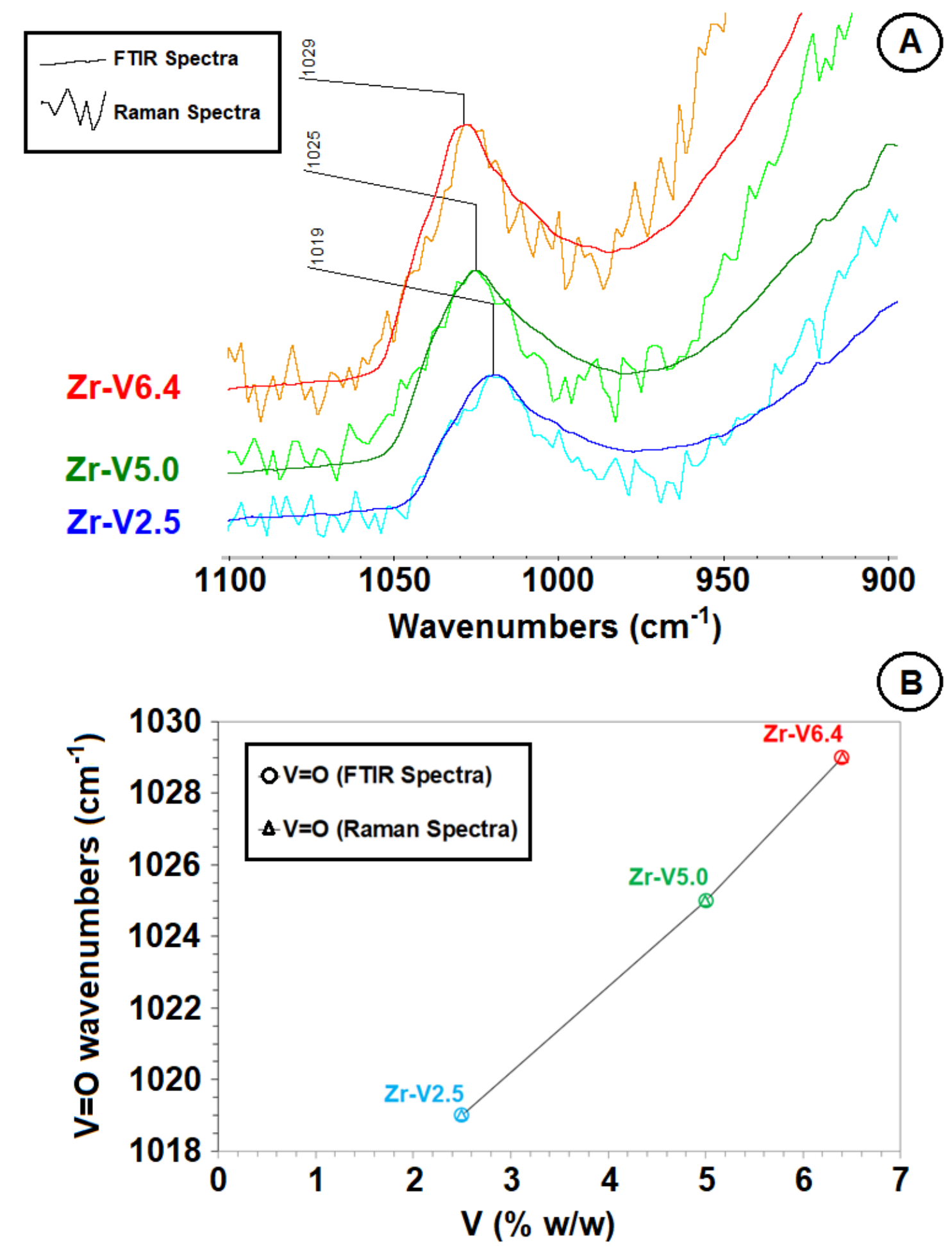

Figure 3. $A$ (top). Infrared and Raman spectra in the $V=O$ region for dehydrated catalysts. $B$ (bottom). (0) Infrared and ( $\Delta$ ) Raman $V=O$ mode frequency vs. vanadia loading for dehydrated catalysts. 


\section{2) Studying catalysts during reaction}

The catalysts were all inactive below $200{ }^{\circ} \mathrm{C}$; above this temperature, the conversion raises gradually. Table S1 shows the activity results obtained by MS and FTIR spectra from the gas phase during propane ODH experiments in the IRRaman reactor at $340{ }^{\circ} \mathrm{C}$. These results are consistent with those obtained with the same samples in a conventional fixed bed microreactor ${ }^{48}$, which validates the catalytic relevance of the data obtained in the IRRaman reactor (i.e., it is a genuine operando reactor) and the temperature control.

These activity data were compared with the evolution of the Raman and FTIR operando spectra (Figure 4). In order to fully characterize the catalysts, spectra were acquired at $340{ }^{\circ} \mathrm{C}$ both in the presence and absence of oxygen, and with an activation flow before and after reaction. FTIR spectra in the $1750-1100 \mathrm{~cm}^{-1}$ region provide information about the adsorbed oxygenated species (Figure 4-1). In the $1100-900 \mathrm{~cm}^{-1}$ region, FTIR bands related to $\mathrm{V}=\mathrm{O}$ bonds are detected (Figure 4-2) and can be directly compared to the Raman results presented in the region $1100-525 \mathrm{~cm}^{-1}$ (Figure 4-3). Adsorbed species were removed by heat treatment in presence of $\mathrm{O}_{2}$ before starting each experiment. 


\section{Initial Spectra \\ Activation flow before reaction}

FTIR Spectra (Adsorbed Species)

FTIR Spectra (V=O Bonds)

Zr-V2.5

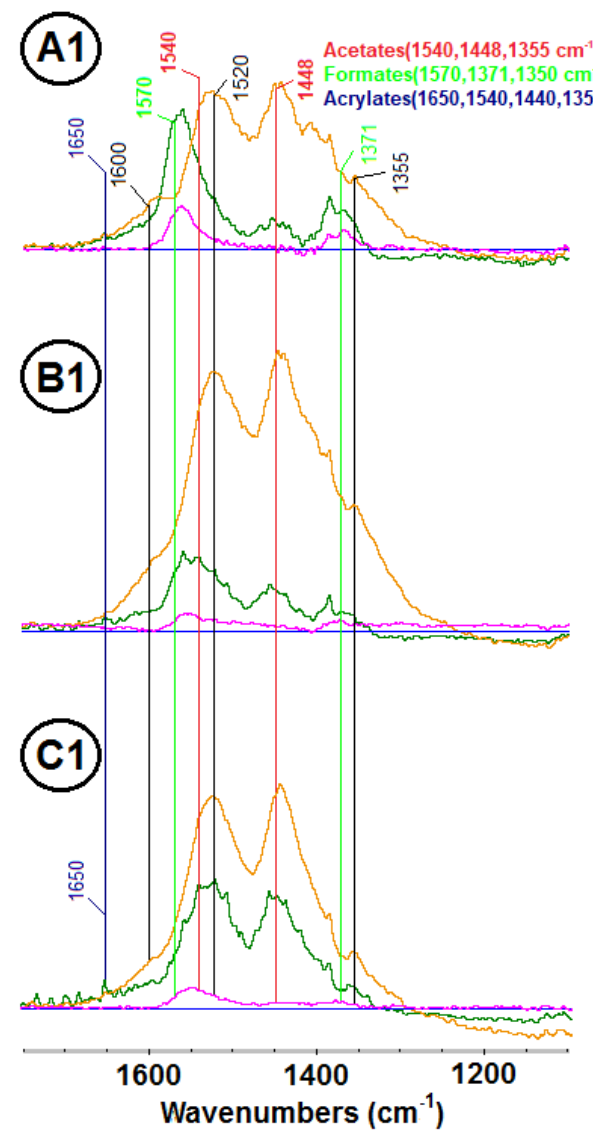

(A2)

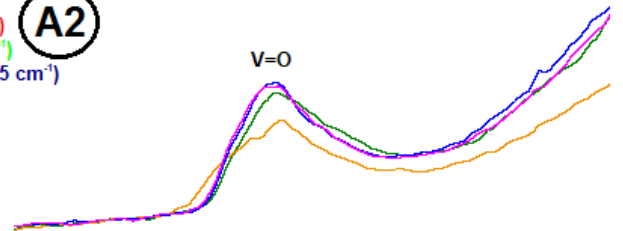

\section{Zr-V5.0}
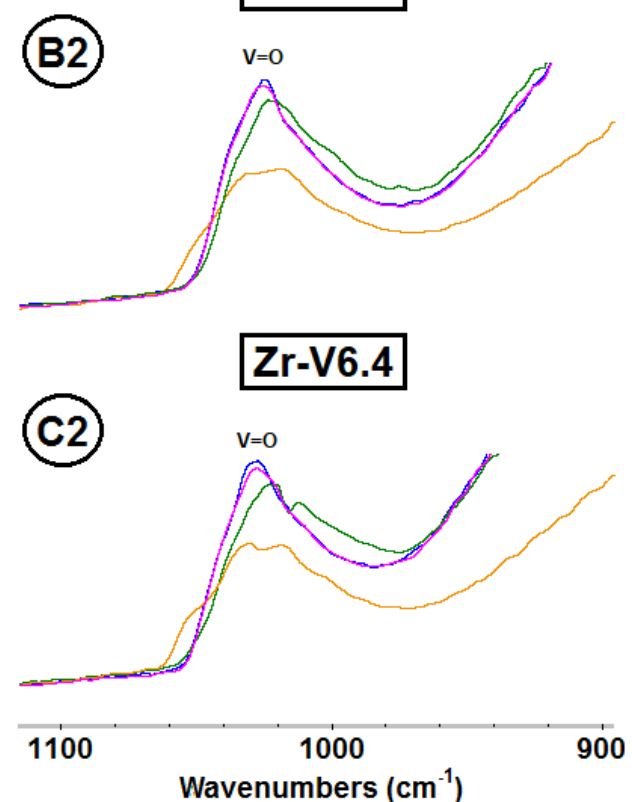

\section{Post-reaction Spectra}

$\rightarrow$ Activation flow

after reaction flow

Raman Spectra (V=O, V-O-V and V-O-Zr Bonds)
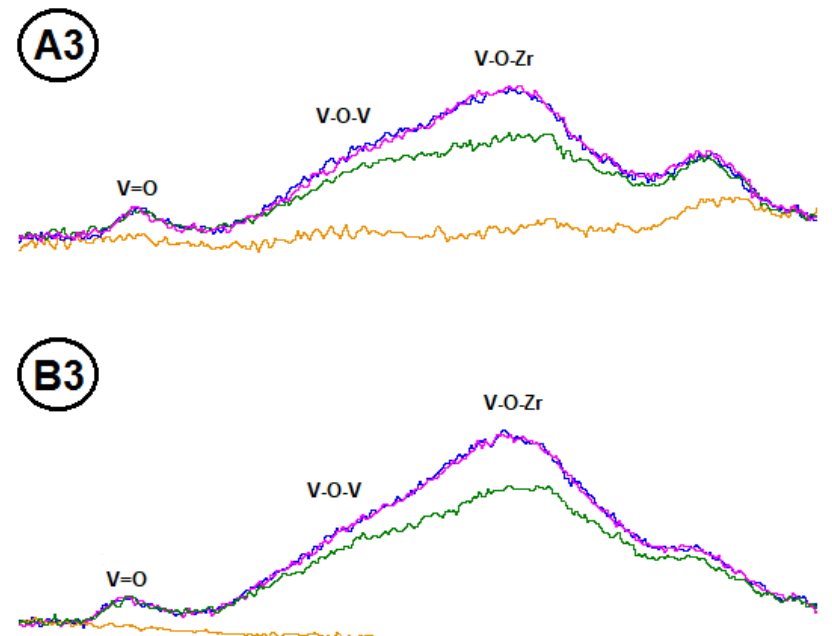

(C3)

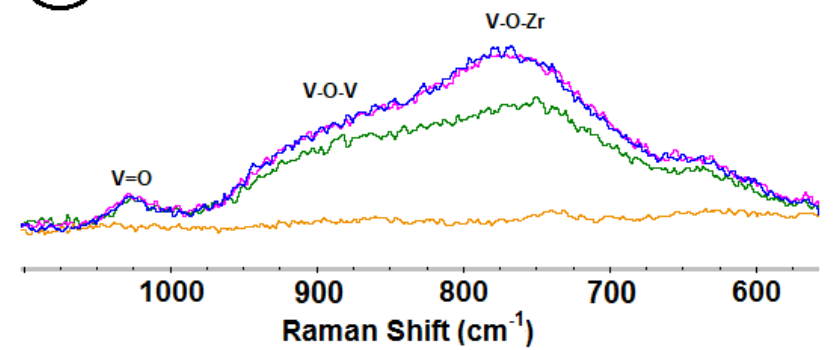

Figure 4. Operando FTIR (1 and 2) and Raman (3) spectra for (A) Zr-V2.5, (B) Zr-V5.0 and (C) Zr-V6.4 at 340ㅡ. IR spectra shown at 1700-1100 $\mathrm{cm}^{-1}$ (1) were all subtracted with the reference spectrum of the sample under activation flow at the same temperature. Green and yellow traces represent experiments using $\mathrm{ODH}$ and $\mathrm{DH}$ feeds, respectively. Spectra represented in green correlate with the activity results presented in Table S1. Blue and pink traces represent experiments using activation flow before and after reaction, respectively. 
The catalysts exhibit some infrared bands in the region of adsorbed species during $\mathrm{ODH}$ reaction (green spectra in Figure 4-1). These bands correspond to a mixture of bidentate acetates $\left(1540,1448\right.$, and $\left.1355 \mathrm{~cm}^{-1}\right)$, acrylates $(\sim 1640$, 1540, 1440, and $\left.1355 \mathrm{~cm}^{-1}\right)$ and bidentate formates $\left(1570,1371\right.$, and $\left.1350 \mathrm{~cm}^{-1}\right)$ 70-75. Interestingly, bands in the same range are also observed at $200^{\circ} \mathrm{C}$, but only for the highest vanadium loading (Figure S2). In these formates are predominant and they remain stable upon oxidation. Being this catalyst, as the others, inactive at $200 \stackrel{\circ}{ } \mathrm{C}$, formate species are thus likely to have a moderate role in the reaction scheme. Conversely, at $340^{\circ} \mathrm{C}$, the adsorbed species are almost completely removed upon reoxidation (Figure 4, pink spectra); the concomitant detection of $\mathrm{CO}_{\mathrm{x}}$ and water in the gas phase suggests that these surface adsorbed species are intermediates of the total oxidation pathway. The proportion of acetates and acrylates with respect to that of formates increases with the vanadium content, especially in the most active catalyst (Zr-V6.4). This could indicate that acetates and acrylates preferentially adsorb on more polymerized vanadium species. A small shift and a slight intensity decrease of the infrared $\mathrm{V}=\mathrm{O}$ modes (Figure 4-2) is apparent during reaction (green spectra) with respect to the initial activated state (blue spectra), this effect being more noticeable as the vanadium content increases. These small perturbations observed during reaction disappear, as the adsorbed oxygenate species, upon reoxidation (pink spectra)., and thus could somehow be associated to the interaction of the $\mathrm{V}=\mathrm{O}$ bond with the adsorbed species. The Raman spectra of all the catalysts (Figure 4-3) show a significant decrease in the intensity of the bands associated to $\mathrm{V}-\mathrm{O}-\mathrm{V}$ and $\mathrm{V}-\mathrm{O}-\mathrm{Zr}$ bonds during reaction (green spectra) with respect to the fresh catalyst (blue spectra). These bands are completely restored upon oxidation of the fresh activated 
catalysts (blue spectra), suggesting that $\mathrm{V}-\mathrm{O}-\mathrm{V}$ and $\mathrm{V}-\mathrm{O}-\mathrm{Zr}$ species participate in the propane $\mathrm{ODH}$ reaction, being most probably the active sites. These results are in agreement with previous findings that determine a higher reactivity of the bridging oxygen ( $\mathrm{V}-\mathrm{O}-\mathrm{V}$ and $\mathrm{V}-\mathrm{O}-\mathrm{Support}$ ) with respect to the terminal oxygen of the vanadyl group ${ }^{77}$.

In additional reaction experiments without $\mathrm{O}_{2}(\mathrm{DH}$; yellow spectra), the FTIR spectra of Figure 4-1 show more adsorbed oxygenates -especially acetates- than in $\mathrm{ODH}$ conditions. As reported in the literature ${ }^{76}$, lattice oxygen is not involved in formates conversion to CO. Conversely, the development of acetates and acrylates implies catalyst reduction (i.e., consumption of lattice oxygen). Therefore, during $\mathrm{DH}$, acetates dominate because only the formates are removed. During $\mathrm{ODH}$, both acetate and formate species are formed and removed, giving rise to a steady state structure characterised by a spectrum which is just a mere linear combination of both IR spectra. These differences are not observed between the $\mathrm{DH}$ and $\mathrm{ODH}$ spectra for the catalysts with higher vanadium content (Zr-V5.0 and Zr-V6.4), since they already present a higher proportion of acetates with respect to formates.

During $\mathrm{DH}$, carbonaceous deposits form, as evidenced by a shoulder around $1600 \mathrm{~cm}^{-1}$ in the FTIR spectra and Raman bands of carbon compounds around 1430 and $1600 \mathrm{~cm}^{-1}$ (Supporting Information, Figure S3). Moreover, the $\mathrm{V}=\mathrm{O}$ mode remains mildly affected in the FTIR spectra (Figure 4-2), although there is a complete depletion of the $\mathrm{V}=\mathrm{O}$ and polyvanadate Raman bands (Figure 4-3).

An interesting aspect is that when the Raman signal is lost the infrared spectra show a split of the vanadyl band in two (or more) modes and these facts must be 
related. We cannot determine the configuration of the supported oxide, but either the symmetry or electronic state of vanadia result in a silent Raman signal or for some reason Raman signal is lost under these conditions whatever the vanadia loading. Further studies with simultaneous IR and Raman reading shall enable understanding what configuration is generated.

The evolution of reaction products during $\mathrm{DH}$ monitored by IR spectroscopy for Zr-V6.4 at $340^{\circ} \mathrm{C}$ is shown in the Supporting Information, Figure S4. The initial products are propylene, $\mathrm{CO}$ and $\mathrm{CO}_{2}$, and their concentration decreases with time as the lattice oxygen of the catalysts is being exhausted. The fact that these oxygenated products are detected during some minutes confirms the participation of lattice oxygen in the reaction, in line with a Mars-Van Krevelen type mechanism. This is confirmed by the major decrease of the $\mathrm{V}-\mathrm{O}-\mathrm{V} / \mathrm{V}-\mathrm{O}-\mathrm{Zr}$ bands, which suggests the contribution of these bridging oxygen atoms to the oxidation. When oxygen is fed again, both the activity and the $\mathrm{V}-\mathrm{O}-\mathrm{V} / \mathrm{V}-\mathrm{O}-\mathrm{Zr}$ bands are recovered, demonstrating the reversibility of the redox behavior of these catalysts. The absence of changes when inert flow is fed after reaction instead of oxygen demonstrates that the catalyst reoxidation (or the recovery of the vanadia bands to the initial state) and the removal of the adsorbed species (mainly acetates and carbonaceous deposits) are only possible if there is oxygen in the gas phase.

In summary, while the operando approach is required to provide the necessary catalytic data to establish structure activity relationships, the simultaneous acquisition of IR and Raman spectra allows an extensive evaluation of the adsorbed species and their impact on the working catalyst. 


\section{Conclusions}

A new multimodal operando reactor-cell was developed for simultaneous Raman and transmission FTIR operando spectrocopies ("IRRaman" reactor) and validated with V-Zr-O catalysts during propane ODHreaction. The combination of complementary spectroscopies allows both the identification of the reaction intermediates (oxygenated species detected by FTIR) and obtaining complete structural information (evolution of $\mathrm{V}=\mathrm{O}$ and $\mathrm{V}-\mathrm{O}-\mathrm{V} / \mathrm{V}-\mathrm{O}-\mathrm{Zr}$ bonds on the catalysts followed by FTIR and Raman). The V=O mode, detected in Raman and infrared, has the same frequency in both spectra, since they are measured under identical conditions. The V-O-V/V-O-Zr oxygen sites were found to be more active than those in the terminal $\mathrm{V}=\mathrm{O}$ bond, shedding additional light on the role of themdifferent oxygen species in the reported Mars-van Krevelen mechanism for zirconia-supported vanadia.

As an outlook, the new operando multimodal device can provide fundamental insight into many reaction mechanisms thanks to its capacity to associate concomitant information from surface adsorbed species and catalyst structure evolution under stream in a single rig, on the same sample, at the same time and under relevant operating conditions. This device could also find useful applications in the study of materials in evolution under heat and/or under controlled atmosphere. 


\section{Acknowledgements}

Authors acknowledge the FEDER-Region Basse-Normandie (France)-CNRS for

a Chaire d'Excellence, which resulted in the implementation of the "IRRaman" rig and a research stay allowing to perform these investigations. This work was also supported by the Spanish Ministry of Economy and Competitiveness and FEDER (CTQ2012-36408, CTQ2015-68654-R and CTM2017-82335-R). J.J.T.H. acknowledges the assistance of the Ministry of Economy and Competitiveness of Spain for the award of a FPI Grant (BES-2013-064425) and the award for performing his stay at ENSICAEN (EEBB-I-16-10749).

\section{References}

(1) Chakrabarti, A.; Ford, M. E.; Gregory, D.; Hu, R.; Keturakis, C. J.; Lwin, S.; Tang, Y.; Yang, Z.; Zhu, M.; Bañares, M. A.; et al. A Decade+ of Operando Spectroscopy Studies. Catal. Today 283, 27-53 (2017), https://doi.org/10.1016/j.cattod.2016.12.012.

(2) Vimont, A.; Thibault-Starzyk, F.; Daturi, M. Analysing and Understanding the Active Site by IR Spectroscopy. Chem. Soc. Rev. 39 (12), 4928-4950 (2010). https://doi.org/10.1039/B919543M.

(3) Marie, O.; Bazin, P.; Daturi, M. Vibrational Spectroscopic Studies of Catalytic Processes on Oxide Surfaces. In Spectroscopic Properties of 
Inorganic and Organometallic Compounds; 2011; pp 34-103.

https://doi.org/10.1039/9781849732833-00034.

(4) Meunier, F. C. The Design and Testing of Kinetically-Appropriate Operando Spectroscopic Cells for Investigating Heterogeneous Catalytic Reactions. Chem. Soc. Rev.39 (12), 4602-4614 (2010). https://doi.org/10.1039/B919705M.

(5) Frenkel, A. I.; Rodriguez, J. A.; Chen, J. G. Synchrotron Techniques for In Situ Catalytic Studies: Capabilities, Challenges, and Opportunities. ACS Catal., 2 (11), 2269-2280 (2012). https://doi.org/10.1021/cs3004006.

(6) Guerrero-Pérez, M. O.; Bañares, M. A. From Conventional in Situ to Operando Studies in Raman Spectroscopy. Catal. Today 113 (1), 48-57 (2006). https://doi.org/10.1016/j.cattod.2005.11.009.

(7) Bañares, M. A. Operando Methodology: Combination of in Situ Spectroscopy and Simultaneous Activity Measurements under Catalytic Reaction Conditions. Catal. Today 100 (1), 71-77 (2005). https://doi.org/10.1016/j.cattod.2004.12.017.

(8) Wachs, I. E.; Roberts, C. A. Monitoring Surface Metal Oxide Catalytic Active Sites with Raman Spectroscopy. Chem. Soc. Rev.39 (12), 5002-5017 (2010). https://doi.org/10.1039/C0CS00145G.

(9) Hunger, M.; Weitkamp, J. In Situ IR, NMR, EPR, and UV/Vis Spectroscopy: Tools for New Insight into the Mechanisms of Heterogeneous Catalysis. Angew. Chem. - Int. Ed. 40 (16), 2954-2971 (2001). 
https://doi.org/10.1002/1521-3773(20010817)40:16<2954::AID-

ANIE2954>3.0.CO;2-\#.

(10) Lysova, A. A.; Koptyug, I. V. Magnetic Resonance Imaging Methods for in Situ Studies in Heterogeneous Catalysis. Chem. Soc. Rev.39 (12), 45854601 (2010). https://doi.org/10.1039/B919540H.

(11) Schoonheydt, R. A. UV-VIS-NIR Spectroscopy and Microscopy of Heterogeneous Catalysts. Chem. Soc. Rev. 39 (12), 5051-5066 (2010). https://doi.org/10.1039/COCS00080A.

(12) Tao, F.; Crozier, P. A. Atomic-Scale Observations of Catalyst Structures under Reaction Conditions and during Catalysis. Chem. Rev.116 (6), 34873539 (2016). https://doi.org/10.1021/cr5002657.

(13) Rousseau, S.; Marie, O.; Bazin, P.; Daturi, M.; Verdier, S.; Harlé, V. Investigation of Methanol Oxidation over Au/Catalysts Using Operando IR Spectroscopy: Determination of the Active Sites, Intermediate/Spectator Species, and Reaction Mechanism. J. Am. Chem. Soc.132 (31), 10832-10841 (2010). https://doi.org/10.1021/ja1028809.

(14) Rasmussen, S. B.; Bañares, M. A.; Bazin, P.; Due-Hansen, J.; Ávila, P.; Daturi, M. Monitoring Catalysts at Work in Their Final Form: Spectroscopic Investigations on a Monolithic Catalyst. Phys. Chem. Chem. Phys.14 (7), 21712177 (2012). https://doi.org/10.1039/C1CP22629K.

(15) Mul, G.; Hamminga, G. M.; Moulijn, J. A. Operando ATR-FTIR Analysis of Liquid-Phase Catalytic Reactions: Can Heterogeneous Catalysts Be 
Observed? Vib. Spectrosc. 34 (1), 109-121 (2004).

https://doi.org/10.1016/j.vibspec.2003.07.004.

(16) Davó-Quiñonero, A.; Bueno-López, A.; Lozano-Castelló, D.; McCue, A. J.; Anderson, J. A. Rapid-Scan Operando InfraredSpectroscopy. ChemCatChem 8 (11), 1905-1908 (2016).

https://doi.org/10.1002/cctc.201600302.

(17) J. Saussey; F. Thibault-Starzyk; B.M. Weckhuysen. In Situ Characterization of Catalysts; American Scientific Publishers: San Diego, 2004; pp 15-31.

(18) Brückner, A.; Kubias, B.; Lücke, B. In Situ-Electron Spin Resonance: A Useful Tool for the Investigation of Vanadium Phosphate Catalysts (VPO) under Working Conditions. Catal. Today 32 (1), 215-222 (1996).

https://doi.org/10.1016/S0920-5861(96)00077-6.

(19) Bentrup, U.; Brückner, A.; Rüdinger, C.; Eberle, H.-J. Elucidating Structure and Function of Active Sites in $\mathrm{VO}_{x} / \mathrm{TiO}_{2}$ Catalysts during Oxyhydrative Scission of 1-Butene by in Situ and Operando Spectroscopy. Appl. Catal. Gen.269 (1), 237-248 (2004).

https://doi.org/10.1016/j.apcata.2004.04.027.

(20) Clausen, B. S.; Steffensen, G.; Fabius, B.; Villadsen, J.; Feidenhans'l, R.; Topsøe, H. In Situ Cell for Combined XRD and On-Line Catalysis Tests:

Studies of Cu-Based Water Gas Shift and Methanol Catalysts. J. Catal. 132 (2), 524-535 (1991). https://doi.org/10.1016/0021-9517(91)90168-4. 
(21) Guerrero-Pérez, M. O.; López-Medina, R.; Rojas-Garcia, E.; Bañares, M. A. XANES Study of the Dynamic States of V-Based Oxide Catalysts under Partial Oxidation Reaction Conditions. Catal. Today 336 (2019) 210-215 https://doi.org/10.1016/j.cattod.2017.12.016.

(22) Woo, S. I.; Hill Jr., C. G. In Situ Raman Spectroscopy Studies of the Hydroformylation of Propylene. J. Mol. Catal. 29 (2), 231-258 (1985). https://doi.org/10.1016/0304-5102(85)87007-3.

(23) Snyder, T. P.; Hill, C. G. Stability of Bismuth Molybdate Catalysts at Elevated Temperatures in Air and under Reaction Conditions. J. Catal. 132 (2), 536-555 (1991). https://doi.org/10.1016/0021-9517(91)90169-5.

(24) Wang, C.-B.; Deo, G.; Wachs, I. E. Interaction of Polycrystalline Silver with Oxygen, Water, Carbon Dioxide, Ethylene, and Methanol: In Situ Raman and Catalytic Studies. J. Phys. Chem. B 103 (27), 5645-5656 (1999).

(25) Tolia, A. A.; Williams, C. T.; Takoudis, C. G.; Weaver, M. J. SurfaceEnhanced Raman Spectroscopy as an in-Situ Real-Time Probe of Catalytic Mechanisms at High Gas Pressures: The CO-NO Reaction on Rhodium. J. Phys. Chem. 99 (13), 4599-4608 (1995). https://doi.org/10.1021/j100013a034.

(26) Guerrero-Pérez, M. O.; Bañares, M. A. Operando Raman Study of Alumina-Supported Sb-V-O Catalyst during Propane Ammoxidation to Acrylonitrile with on-Line Activity Measurement. Chem. Commun.12, 12921293 (2002). https://doi.org/10.1039/B202556F.

(27) Guerrero-Pérez, M. O.; Bañares, M. A. Operando Raman-GC Study of Supported Alumina Sb- and V-Based Catalysts: Effect of Sb/V Molar Ratio and 
Total $\mathrm{Sb}+\mathrm{V}$ Coverage in the Structure of Catalysts during Propane Ammoxidation. J. Phys. Chem. C 111(3), 1315-1322 (2007). https://doi.org/10.1021/jp065387s.

(28) Guerrero-Pérez, M. O.; Rojas, E.; Gutiérrez-Alejandre, A.; Ramírez, J.; Sánchez-Minero, F.; Fernández-Vargas, C.; Bañares, M. A. In Situ Raman Studies during Sulfidation, and Operando Raman-GC during Ammoxidation Reaction Using Nickel-Containing Catalysts: A Valuable Tool to Identify the Transformations of Catalytic Species. Phys. Chem. Chem. Phys. 13 (20), 92609267 (2011). https://doi.org/10.1039/C0CP02242J.

(29) López-Medina, R.; Fierro, J. L. G.; Guerrero-Pérez, M. O.; Bañares, M. A. Structural Changes Occurring at the Surface of Alumina-Supported Nanoscaled Mo-V-Nb-(Te)-O Catalytic System during the Selective Oxidation of Propane to Acrylic Acid. Appl. Catal. Gen. 406 (1), 34-42 (2011). https://doi.org/10.1016/j.apcata.2011.08.002.

(30) Weckhuysen, B. M. Determining the Active Site in a Catalytic Process: Operando Spectroscopy Is More than a Buzzword. Phys. Chem. Chem. Phys. 5 (20), 4351-4360 (2003). https://doi.org/10.1039/B309650P.

(31) Mondelli, C.; Ferri, D.; Grunwaldt, J.-D.; Krumeich, F.; Mangold, S.; Psaro, R.; Baiker, A. Combined Liquid-Phase ATR-IR and XAS Study of the BiPromotion in the Aerobic Oxidation of Benzyl Alcohol over $\mathrm{Pd} / \mathrm{Al}_{2} \mathrm{O}_{3} . \mathrm{J}$. Catal.252 (1), 77-87 (2007). https://doi.org/10.1016/j.jcat.2007.09.013.

(32) Cats, K. H.; Weckhuysen, B. M. Combined Operando X-Ray Diffraction/Raman Spectroscopy of Catalytic Solids in the Laboratory: The 
$\mathrm{Co} / \mathrm{TiO}_{2}$ Fischer-Tropsch Synthesis Catalyst Showcase. ChemCatChem 8(8), 1531-1542 (2016). https://doi.org/10.1002/cctc.201600074.

(33) Beale, A. M.; Eerden, A. M. J. van der; Kervinen, K.; Newton, M. A.;

Weckhuysen, B. M. Adding a Third Dimension to Operando Spectroscopy: A Combined UV-Vis, Raman and XAFS Setup to Study Heterogeneous Catalysts under Working Conditions. Chem. Commun. 24, 3015-3017 (2005). https://doi.org/10.1039/B504027B.

(34) Patlolla, A.; Carino, E. V.; Ehrlich, S. N.; Stavitski, E.; Frenkel, A. I. Application of Operando XAS, XRD, and Raman Spectroscopy for Phase Speciation in Water Gas Shift Reaction Catalysts. ACS Catal. 2 (11), 22162223 (2012). https://doi.org/10.1021/cs300414c.

(35) Brückner, A. Killing Three Birds with One Stone-Simultaneous Operando EPR/UV-Vis/Raman Spectroscopy for Monitoring Catalytic Reactions. Chem. Commun. 2005, No. 13, 1761-1763. https://doi.org/10.1039/B418790C.

(36) Bentrup, U. Combining in Situ Characterization Methods in One Set-up: Looking with More Eyes into the Intricate Chemistry of the Synthesis and Working of Heterogeneous Catalysts. Chem. Soc. Rev. 39 (12), 4718-4730 (2010). https://doi.org/10.1039/B919711G.

(37) Airaksinen, S. M. K.; Krause, A. O. I.; Sainio, J.; Lahtinen, J.; Chao, K.; Guerrero-Pérez, M. O.; Bañares, M. A. Reduction of Chromia/Alumina Catalyst Monitored by DRIFTS-Mass Spectrometry and TPR-Raman Spectroscopy. 
Phys. Chem. Chem. Phys. 5 (20), 4371-4377 (2003).

https://doi.org/10.1039/B305802F.

(38) Bourdon, G. L.; Adar, F.; Moreau, M.; Morel, S.; Reffner, J.; Mamede, A.S.; Dujardin, C.; Payen, E. In Situ Characterization by Raman and IR Vibrational Spectroscopies on a Single Instrument: DeNOx Reaction over a Pd/Y-Al2O3 Catalyst. Phys. Chem. Chem. Phys. 5 (20), 4441-4444 (2003). https://doi.org/10.1039/B306045B.

(39) Li, G.; Hu, D.; Xia, G.; White, J. M.; Zhang, C. High Throughput Operando Studies Using Fourier Transform Infrared Imaging and Raman Spectroscopy. Rev. Sci. Instrum. 79 (7), 074101 (2008). https://doi.org/10.1063/1.2949389.

(40) Li, G.; Hu, D.; Xia, G.; Conrad, Zhang, Z. Methanol Partial Oxidation on $\mathrm{MoO}_{3} / \mathrm{SiO}_{2}$ Catalysts: Application of Vibrational Spectroscopic Imaging Techniques in a High Throughput Operando Reactor. Top. Catal. 52 (10), 1381-1387 (2009). https://doi.org/10.1007/s11244-009-9325-y.

(41) Urakawa, A.; Maeda, N.; Baiker, A. Space- and Time-Resolved Combined DRIFT and Raman Spectroscopy: Monitoring Dynamic Surface and Bulk Processes during NO× Storage Reduction. Angew. Chem. Int. Ed. 47 (48), 9256-9259 (2008). https://doi.org/10.1002/anie.200804077.

(42) Visconti, C. G.; Lietti, L.; Manenti, F.; Daturi, M.; Corbetta, M.; Pierucci, S.; Forzatti, P. Spectrokinetic Analysis of the NOx Storage Over a Pt-Ba/Al $\mathrm{O}_{3}$ Lean NOx Trap Catalyst. Top. Catal. 56 (1), 311-316 (2013). https://doi.org/10.1007/s11244-013-9972-x. 
(43) Grabowski, R. Kinetics of Oxidative Dehydrogenation of C2-C3 Alkanes on Oxide Catalysts. Catal. Rev. - Sci. Eng. 48 (2), 199-268 (2006). https://doi.org/10.1080/01614940600631413.

(44) Carrero, C. A.; Schloegl, R.; Wachs, I. E.; Schomaecker, R. Critical Literature Review of the Kinetics for the Oxidative Dehydrogenation of Propane over Well-Defined Supported Vanadium Oxide Catalysts. ACS Catal., 4 (10), 3357-3380 (2014). https://doi.org/10.1021/cs5003417.

(45) Cavani, F.; Ballarini, N.; Cericola, A. Oxidative Dehydrogenation of Ethane and Propane: How Far from Commercial Implementation? Catal. Today 127 (1-4), 113-131 (2007). https://doi.org/10.1016/j.cattod.2007.05.009.

(46) Kung, H. H. Oxidative Dehydrogenation of Light (C2 to C4) Alkanes. In Advances in Catalysis; Eley, D. D., Pines, H., Haag, W. O., Eds.; Academic Press, 1994; Vol. 40, pp 1-38. https://doi.org/10.1016/S0360-0564(08)60655-0.

(47) Chakraborty, S.; Nayak, S. C.; Deo, G. TiO2/SiO2 Supported Vanadia Catalysts for the ODH of Propane. Catal. Today 254, 62-71 (2015). https://doi.org/10.1016/j.cattod.2015.01.047.

(48) Ternero-Hidalgo, J. J.; Torres-Liñán, J.; Guerrero-Pérez, M. O.; Rodríguez-Mirasol, J.; Cordero, T. Electrospun Vanadium Oxide Based Submicron Diameter Fiber Catalysts. Part I: Preparation Procedure and Propane ODH Application. Catal. Today 325, 131-143 (2019). https://doi.org/10.1016/j.cattod.2018.10.073.

(49) Ternero-Hidalgo, J. J.; Guerrero-Pérez, M. O.; Rodríguez-Mirasol, J.; Cordero, T. Electrospun Vanadium Oxide Based Submicron Diameter Fiber 
Catalysts. Part II: Effect of Chemical Formulation and Dopants. Catal. Today 325, 144-150 (2019). https://doi.org/10.1016/j.cattod.2018.10.072.

(50) Wuttke, S.; Bazin, P.; Vimont, A.; Serre, C.; Seo, Y.-K.; Hwang, Y. K.; Chang, J.-S.; Férey, G.; Daturi, M. Discovering the Active Sites for C3 Separation in MIL-100(Fe) by Using Operando IR Spectroscopy. Chem. - Eur. J. 18 (38), 11959-11967 (2012). https://doi.org/10.1002/chem.201201006.

(51) Thomas, S.; Marie, O.; Bazin, P.; Lietti, L.; Visconti, C. G.; Corbetta, M.; Manenti, F.; Daturi, M. Modelling a Reactor Cell for Operando IR Studies: From Qualitative to Fully Quantitative Kinetic Investigations. Catal. Today 283, 176184 (2017). https://doi.org/10.1016/j.cattod.2016.07.008.

(52) Rasmussen, S. B.; Perez-Ferreras, S.; Bañares, M. A.; Bazin, P.; Daturi, M. Does Pelletizing Catalysts Influence the Efficiency Number of Activity Measurements? Spectrochemical Engineering Considerations for an Accurate Operando Study. ACS Catal. 3 (1), 86-94 (2013). https://doi.org/10.1021/cs300687v.

(53) El-Roz, M.; Bazin, P.; Thibault-Starzyk, F. An Operando-IR Study of Photocatalytic Reaction of Methanol on New *BEA Supported $\mathrm{TiO}_{2}$ Catalyst. Catal. Today 205, 111-119 (2013). https://doi.org/10.1016/j.cattod.2012.08.023.

(54) Fernandez, L.; Sanchez, E.; Panizza, M.; Carnasciali, M. M.; Busca, G. Vibrational and Electronic Spectroscopic Properties of Zirconia Powders. J. Mater. Chem. 11 (7), 1891-1897 (2001). https://doi.org/10.1039/b100909p.

(55) Ward, J. W. Nature of Sites Formed on Zeolites by Addition of Water. J. Phys. Chem. 72 (7), 2689-2690 (1968). https://doi.org/10.1021/j100853a090. 
(56) Ward, J. W. The Nature of Active Sites on Zeolites: IV. The Influence of Water on the Acidity of X and Y Type Zeolites. J. Catal. 11 (3), 238-250 (1968). https://doi.org/10.1016/0021-9517(68)90037-7.

(57) Lietti, L.; Forzatti, P.; Ramis, G.; Busca, G.; Bregani, F. Potassium Doping of Vanadia/Titania de-NOxing Catalysts: Surface Characterisation and Reactivity Study. Appl. Catal. B Environ. 3 (1), 13-35 (1993). https://doi.org/10.1016/0926-3373(93)80065-L.

(58) Magg, N.; Immaraporn, B.; Giorgi, J. B.; Schroeder, T.; Bäumer, M.; Döbler, J.; Wu, Z.; Kondratenko, E.; Cherian, M.; Baerns, M.; et al. Vibrational Spectra of Alumina- and Silica-Supported Vanadia Revisited: An Experimental and Theoretical Model Catalyst Study. J. Catal.226 (1), 88-100 (2004). https://doi.org/10.1016/j.jcat.2004.04.021.

(59) Wachs, I. E. Raman and IR Studies of Surface Metal Oxide Species on Oxide Supports: Supported Metal Oxide Catalysts. Catal. Today 27 (3), 437455 (1996). https://doi.org/10.1016/0920-5861(95)00203-0.

(60) Bañares, M. A.; Wachs, I. E. Molecular Structures of Supported Metal Oxide Catalysts under Different Environments. J. Raman Spectrosc. 33 (5), 359-380 (2002). https://doi.org/10.1002/jrs.866.

(61) Guerrero-Pérez, M. O.; Fierro, J. L. G.; Vicente, M. A.; Bañares, M. A. Effect of $\mathrm{Sb} / \mathrm{V}$ Ratio and of $\mathrm{Sb}+\mathrm{V}$ Coverage on the Molecular Structure and Activity of Alumina-Supported Sb-V-O Catalysts for the Ammoxidation of Propane to Acrylonitrile. J. Catal. 206 (2), 339-348 (2002). https://doi.org/10.1006/jcat.2001.3494. 
(62) Christodoulakis, A.; Machli, M.; Lemonidou, A. A.; Boghosian, S. Molecular Structure and Reactivity of Vanadia-Based Catalysts for Propane Oxidative Dehydrogenation Studied by in Situ Raman Spectroscopy and Catalytic Activity Measurements. J. Catal. 222 (2), 293-306 (2004). https://doi.org/10.1016/j.jcat.2003.10.007.

(63) Eisenbach, D.; Gallei, E. Infrared Spectroscopic Investigations Relating to Coke Formation on Zeolites: I. Adsorption of Hexene-1 and n-Hexane on Zeolites of Type Y. J. Catal. 56 (3), 377-389 (1979). https://doi.org/10.1016/0021-9517(79)90130-1.

(64) Datka, J.; Sarbak, Z.; Eischens, R. P. Infrared Study of Coke on Alumina and Zeolite. J. Catal. 145 (2), 544-550 (1994). https://doi.org/10.1006/jcat.1994.1065.

(65) Daturi, M.; Binet, C.; Lavalley, J. C.; Blanchard, G. Surface FTIR Investigations on $\mathrm{Ce}_{x} \mathrm{Zr}_{1-\mathrm{x}} \mathrm{O}_{2}$ System. Surf. Interface Anal. 30 (1), 273-277 (2000). https://doi.org/10.1002/1096-9918(200008)30:1<273::AIDSIA715>3.0.CO;2-G.

(66) Bando, K. K.; Sayama, K.; Kusama, H.; Okabe, K.; Arakawa, H. In-Situ FT-IR Study on $\mathrm{CO}_{2}$ Hydrogenation over $\mathrm{Cu}$ Catalysts Supported on $\mathrm{SiO}_{2}$, $\mathrm{Al}_{2} \mathrm{O}_{3}$, and $\mathrm{TiO}_{2}$. Appl. Catal. Gen. 165 (1), $391-409$ (1997). https://doi.org/10.1016/S0926-860X(97)00221-4.

(67) Ramis, G.; Busca, G.; Lorenzelli, V. Low-Temperature CO2 Adsorption on Metal Oxides: Spectroscopic Characterization of Some Weakly Adsorbed 
Species. Mater. Chem. Phys.29 (1), 425-435 (1991).

https://doi.org/10.1016/0254-0584(91)90037-U.

(68) Dinse, A.; Frank, B.; Hess, C.; Habel, D.; Schomäcker, R. Oxidative Dehydrogenation of Propane over Low-Loaded Vanadia Catalysts: Impact of the Support Material on Kinetics and Selectivity. J. Mol. Catal. Chem. 289 (1-2), 28-37 (2008). https://doi.org/10.1016/j.molcata.2008.04.007.

(69) Blasco, T.; Nieto, J. M. L. Oxidative Dyhydrogenation of Short Chain Alkanes on Supported Vanadium Oxide Catalysts. Appl. Catal. Gen. 157 (1), 117-142 (1997). https://doi.org/10.1016/S0926-860X(97)00029-X.

(70) Sanchez Escribano, V.; Busca, G.; Lorenzelli, V. Fourier Transform Infrared Spectroscopic Studies of the Reactivity of Vanadia-Titania Catalysts toward Olefins. 1. Propylene. J. Phys. Chem. 94 (26), 8939-8945 (1990). https://doi.org/10.1021/j100389a017.

(71) Baldi, M.; Finocchio, E.; Pistarino, C.; Busca, G. Evaluation of the Mechanism of the Oxy-Dehydrogenation of Propane over Manganese Oxide. Appl. Catal. Gen. 173 (1), 61-74 (1998). https://doi.org/10.1016/S0926860X(98)00129-X.

(72) El-Roz, M.; Bazin, P.; Daturi, M.; Thibault-Starzyk, F. Operando Infrared (IR) Coupled to Steady-State Isotopic Transient Kinetic Analysis (SSITKA) for Photocatalysis: Reactivity and Mechanistic Studies. ACS Catal. 3 (12), 27902798 (2013). https://doi.org/10.1021/cs4006088. 
(73) Alcock, N. W.; Tracy, V. M.; Waddington, T. C. Acetates and AcetatoComplexes. Part 2. Spectroscopic Studies. J. Chem. Soc. Dalton Trans. 21, 2243-2246 (1976). https://doi.org/10.1039/DT9760002243.

(74) Collins, S. E.; Baltanás, M. A.; Bonivardi, A. L. An Infrared Study of the Intermediates of Methanol Synthesis from Carbon Dioxide over $\mathrm{Pd} / \beta-\mathrm{Ga}_{2} \mathrm{O}_{3} . \mathrm{J}$. Catal. 226 (2), 410-421 (2004). https://doi.org/10.1016/j.jcat.2004.06.012.

(75) Davydov, A. Molecular spectroscopy of oxide catalyst surfaces, Wiley, 2003, p. 454.

(76) Finocchio, E.; Busca, G.; Lorenzelli, V.; Escribano, V. S. FTIR Studies on the Selective Oxidation and Combustion of Light Hydrocarbons at Metal Oxide Surfaces. Part 2.-Propane and Propene Oxidation on $\mathrm{Co}_{3} \mathrm{O}_{4}$. J. Chem. Soc. Faraday Trans. 92 (9), 1587-1593 (1996).

https://doi.org/10.1039/FT9969201587.

(77) Lewandowska, A. E.; Calatayud, M.; Lozano-Diz, E.; Minot, C.; Bañares, M. A. Combining Theoretical Description with Experimental in Situ Studies on the Effect of Alkali Additives on the Structure and Reactivity of Vanadium Oxide Supported Catalysts. Catal. Today 139 (3), 209-213 (2008).

https://doi.org/10.1016/j.cattod.2008.04.049. 


\section{Supporting information}

Operando reactor-cell with simultaneous transmission FTIR \& Raman characterization (IRRaman) for the study of gas-phase reactions with solid catalysts

Juan José Ternero-Hidalgo ${ }^{1}$, María Olga Guerrero-Pérez ${ }^{1 *}$, José Rodríguez-

Mirasol1, Tomás Cordero ${ }^{1}$, Miguel A. Bañares ${ }^{2 *}$, Raquel Portela², Philippe

Bazin $^{3}$, Guillaume Clet ${ }^{3}$, Marco Daturi ${ }^{*}$

1 Universidad de Málaga, Departamento de Ingeniería Química, E29071

Málaga, Spain (oguerrero@uma.es)

${ }^{2}$ Instituto de Catálisis y Petroleoquímica, CSIC, E28049 Madrid, Spain

(miguel.banares@csic.es)

${ }^{3}$ NormandieUniv, ENSICAEN, UNICAEN, CNRS, LCS, 14000 Caen, France

(marco.daturi@ensicaen.fr)

\section{Contents:}

1. Details on catalyst synthesis.

2. Details on the "IRRaman" reactor cell configuration.

3. Details on the catalytic test conditions and methods for the calculation of conversion, selectivity and TOF.

4. Catalytic and spectroscopic results.

5. References.

Figures and Tables:

- Table S1. Catalytic results at a relevant temperature

- Figure S1. XRD patterns of the catalysts (Zr-V2.5, Zr-V5.0 and Zr-V6.4).

- Figure S2. Operando FTIR and Raman spectra for Zr-V2.5, Zr-V5.0 and $\mathrm{Zr}-\mathrm{V} 6.4$ at $200^{\circ} \mathrm{C}$.

- Figure S3. Operando Raman spectra for Zr-V2.5, Zr-V5.0 and Zr-V6.4 in the $1300-1600 \mathrm{~cm}^{-1}$ region during $\mathrm{DH}$ reaction (20\% propane in $\mathrm{He}$ ) at 300 and $340^{\circ} \mathrm{C}$.

- Figure S4. Evolution of the gas phase with time. FTIR spectra of Zr-V6.4 catalyst during $\mathrm{DH}$ reaction $\left(20 \% \mathrm{C}_{3} \mathrm{H}_{8}\right.$ in $\left.\mathrm{Ar}\right)$ at $340^{\circ} \mathrm{C}$. 


\section{Catalyst synthesis}

Zirconium (IV) propoxide solution (Sigma-Aldrich, CAS: 23519-77-9, 70 wt. \% in 1-propanol), polyvinylpyrrolidone (PVP) (Sigma-Aldrich, CAS: 9003-39-8, Mw

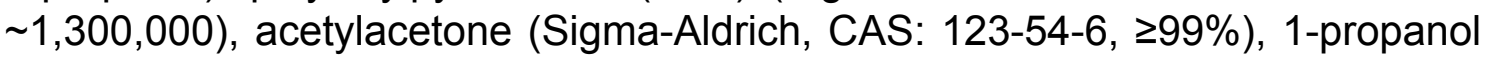
(Sigma-Aldrich, CAS: $71-23-8, \geq 99.5 \%$ ) and vanadyl acetylacetonate (SigmaAldrich, CAS: $3153-26-2, \geq 97.0 \%$ ) were used as starting materials. The catalysts were prepared by electrospinning. The synthesis of the solutions has previously been described i. Briefly, the starting polymer solution was prepared by dissolving $2.100 \mathrm{~g}$ of the zirconium fibers precursor (zirconium (IV) propoxide) and $0.317 \mathrm{~g}$ of PVP in $2.984 \mathrm{~g}$ of 1-propanol solventwith $0.450 \mathrm{~g}$ of acetylacetone. Then, vanadyl acetylacetonate was added to three fractions of this polymer solution to obtain final fibers with nominal vanadium mass concentrations of $2.5 \% \quad(Z r-V 2.5), 5.0 \% \quad(Z r-V 5.0)$ and $6.4 \% \quad(Z r-V 6.4)$. Subsequently, the three polymer solutions were vigorously stirred for $24 \mathrm{~h}$ at room temperature. The electrospinning equipment and procedure have alsobeen described in previous articles $\mathrm{s}^{\mathrm{i}, \mathrm{ii}}$. The electrospun fibers were calcined in air flow $\left(150 \mathrm{~mL} \cdot \mathrm{min}^{-1} \mathrm{STP}\right)$ at $500{ }^{\circ} \mathrm{C}$ in a conventional tubular furnace, with a heating rate of $10^{\circ} \mathrm{C} \cdot \mathrm{min}^{-1}$ followed by $6 \mathrm{~h}$ dwell time in order to eliminate the organic part and the remaining solvent, and to stabilize the zirconia fibers. The final vanadium mass concentration obtained by XPS analysis of $\mathrm{Zr}-\mathrm{V} 2.5, \mathrm{Zr}-$ V5.0 and Zr-V6.4 samples was reported to be $2.7,4.9$ and $6.0 \%$, respectively ${ }^{\mathrm{i}, \mathrm{ii}}$.

\section{The "IRRaman" reactor}

The IR-Raman operando rig was adapted from a home-made operando IR reactor-cell (the so-called "Sandwich" reactor) iii. The cell was notably modified by replacing the two $\mathrm{KBr}$ windows positioned on one side of the cell by a stainless steel cylinder. Two holes were drilled in the cylinder, one to accommodate the Raman probe and another one for a dedicated small $\mathrm{KBr}$ window $(\mathrm{d}=4 \mathrm{~mm})$ to let the IR beam pass through. Air tightness was guaranteed via Kalrez O-rings. The position of the Raman probe, and thus the distance to the pellet surface (approximately 1 $\mathrm{mm}$ ), is adjustable to optimize the signal intensity. The pellet temperature is measured via a calibrated thermocouple placed on the sample holder to ensure proper temperature control independently of the new reactor configuration and construction materials.

\section{ODH reaction conditions}

Three catalytic materials (Zr-V2.5, Zr-V5.0 and Zr-V6.4) were pressed into selfsupported wafers and tested for $\mathrm{ODH}$ in the IRRaman operando reactor. The weight of catalyst $\left(\mathrm{W}_{\text {cat }}\right)$ and the total volumetric gas flow $\left(\mathrm{F}_{\mathrm{T}}\right)$ were $31.5 \mathrm{mg}$ and $18.1 \mathrm{~mL} \cdot \mathrm{min}^{-1}$, respectively, resulting in a space-time $\left(\mathrm{W}_{\text {cat }} / \mathrm{F}_{\mathrm{C} 3 \mathrm{H} 8}\right)$ of 0.53 $\mathrm{g}_{\mathrm{cat}} \cdot \mathrm{s} \cdot \mathrm{mL}^{-1} \mathrm{C} 3 \mathrm{H} 8$. The reaction temperature was varied from 200 to $340^{\circ} \mathrm{C}$. Two different gas mixtures were used in the ODH experiments, an activation flow of $10 \%$ oxygen in argon, and a reaction flow consisting of a mixture of $20 \%$ propane and $10 \%$ oxygen in argon. Dehydrogenation (DH) experiments were also carried out without oxygen in the activation and reaction flows. Gas lines were heated at $60^{\circ} \mathrm{C}$ before and after the reaction-cell to pre-heat the reaction mixture and to avoid products condensation. 
The samples were first dehydrated by heat treatment under activation flow from room temperature to $340^{\circ} \mathrm{C}$ with a heating rate of $5^{\circ} \mathrm{C} \cdot \mathrm{min}^{-1}$. After dehydration and equilibration at the selected reaction temperature, the samples were submitted toactivation and reaction flows with and without oxygen in different order. The conditions were changed when the steady state was achieved.

Operando FTIR and operando Raman spectra of the catalysts were acquired every 2 and $4 \mathrm{~min}$, respectively. Reactants and products of the gas phase were analyzed online by FTIR gas cell (one spectrum every $2 \mathrm{~min}$ ), and mass spectrometry (one measurement every $3 \mathrm{~s}$ ). Under reaction flow the carbon molar balances were always attained with a maximum error of $5 \%$. Propane or oxygen conversion $\left(\mathrm{X}_{\mathrm{C}_{3} \mathrm{H}_{8}}\right.$ or $\mathrm{X}_{\mathrm{O}_{2}}$, respectively) and the selectivity to product " $\mathrm{i}$ " ( $\mathrm{S}_{\mathrm{i}}$ ) were calculated as follows:

$$
\begin{gathered}
X_{i}(\%)=\frac{\dot{F}_{o, i}-\dot{F}_{i}}{\dot{F}_{o, i}} 100 \\
\mathrm{~S}_{\mathrm{i}}(\%)=\frac{\mathrm{n}_{\mathrm{i}} \dot{\mathrm{F}}_{\mathrm{i}}}{\mathrm{n}_{\mathrm{C}_{3} \mathrm{H}_{8}} \dot{\mathrm{F}}_{0, \mathrm{C}_{3} \mathrm{H}_{8}} \mathrm{X}_{\mathrm{C}_{3} \mathrm{H}_{8}}} 100
\end{gathered}
$$

where $\dot{F}_{o, i}$ and $\dot{F}_{i}$ are the molar flows of "i" reactant/product in the inlet and in the outlet streams, respectively, and $n_{i}$ is the number of carbon atoms per molecule of "i" compound $\left(\mathrm{n}_{\mathrm{C}_{3} \mathrm{H}_{8}}=3\right)$.

Turn-over frequency (TOF) was calculated from Eq. S3; it quantifies the specific activity under defined reaction conditions per vanadium atom describing the number of converted moles of propane per mol of vanadium and time:

$$
\text { TOF }=\frac{\dot{\mathrm{F}}_{0, \mathrm{C}_{3} \mathrm{H}_{8}} \mathrm{X}_{\mathrm{C}_{3} \mathrm{H}_{8} \mathrm{M}_{\mathrm{V}}}}{\mathrm{W}_{\mathrm{cat}} \mathrm{W}_{\mathrm{V}}}
$$

where $M_{V}$ is the molar mass of vanadium and $W_{V}$ the mass of vanadium per gram of catalyst.

The TOF values are calculated assuming that all vanadium atoms are exposed on the catalysts, hypothesis supported by the absence of crystalline vanadia observed by Raman and by the fact that the nominal vanadia loading and the surface vanadia concentration calculated from XPS data are very similar.

Blank experiments were performed under reaction flow without catalyst and with a vanadium-free zirconia sample, in order to discard a possible contribution of the homogeneous phase reaction and/or of the zirconia support to the propane $\mathrm{ODH}$ catalytic results at the temperatures studied. In both cases propane conversion values were negligible. 
4. Catalytic and spectroscopic results.

Table S1. Activity results obtained during the operando experiments in the IRRaman reactor at $340^{\circ} \mathrm{C}$ (Catalyst weight: $31.5 \mathrm{mg}$, total flow: $18,1 \mathrm{~mL} \cdot \mathrm{min}^{-1}$, space-time: $0.53 \mathrm{~g} \cdot \mathrm{s} \cdot \mathrm{mL}_{\mathrm{C} 3 \mathrm{H}^{-1}}{ }^{-1}$. Results are reported in steady state where no significant deactivation was observed.

\begin{tabular}{c|c|c|c|c|c|c}
\hline Sample & $\begin{array}{c}\mathbf{X}_{\mathrm{C} 3 \mathrm{H} 8} \\
\mathbf{( \% )}\end{array}$ & $\begin{array}{c}\mathbf{X}_{\mathrm{O} 2} \\
\mathbf{( \% )}\end{array}$ & $\begin{array}{c}\mathbf{S}_{\mathrm{C} 3 \mathrm{H} 6} \\
\mathbf{( \% )}\end{array}$ & $\begin{array}{c}\mathbf{S}_{\mathrm{COx}} \\
\mathbf{( \% )}\end{array}$ & $\begin{array}{c}\mathbf{Y}_{\mathrm{C} 3 \mathrm{H} 6} \\
\mathbf{( \% )}\end{array}$ & $\begin{array}{c}\text { TOF }^{\mathrm{a}} \\
\left(\mathbf{1 0}^{-3} \cdot \mathbf{s}^{-1}\right)\end{array}$ \\
\hline Zr-V2.5 & 1.3 & 6.6 & 71.4 & $\mathbf{2 8 . 6}$ & 0.93 & 2.02 \\
Zr-V5.0 & 3.2 & 10.9 & 75.8 & 24.2 & 2.42 & 2.74 \\
Zr-V6.4 & 5.3 & 24.3 & 58.5 & 41.5 & 3.10 & 3.71 \\
\hline
\end{tabular}

a TOF based on XPS analyses.

Table S2. XPS results previously obtained for catalyst compositions ', used to calculate the TOF values.

\begin{tabular}{ccccc}
\hline \multirow{2}{*}{ Sample } & \multicolumn{4}{c}{ XPS (wt \%) } \\
\cline { 2 - 5 } & V2p & Zr3d & O1s & C1s \\
\hline Zr-V2.5 & 2.7 & 66.1 & 24.2 & 7.0 \\
Zr-V5.0 & 4.9 & 64.3 & 27.9 & 2.9 \\
Zr-V6.4 & 6.0 & 59.8 & 24.8 & 9.4 \\
\hline
\end{tabular}

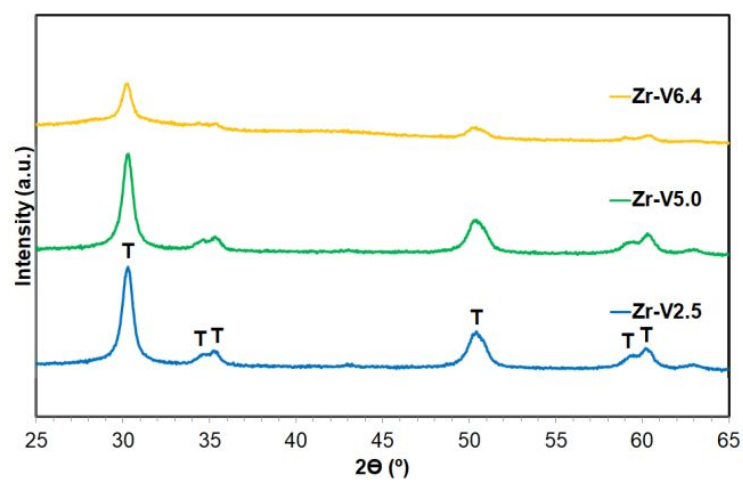

Figure S1. XRD patterns of the catalysts (Zr-V2.5, Zr-V5.0 and Zr-V6.4). Tetragonal ( $\mathrm{T}$ ) $\mathrm{ZrO}_{2}$ (JCPDS 01-079-1769) is found in all the diffractograms. 


\section{Initial Spectra}

Activation flow before reaction

FTIR Spectra (Adsorbed Species)

(A1)

Acetates $(1540,1448,1355 \mathrm{~cm}$
Formates

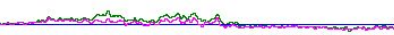

(B1)

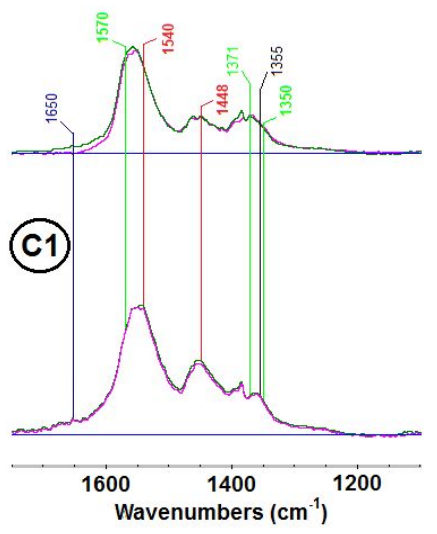

Reaction Spectra

- Reaction flow

FTIR Spectra (V=O Bonds)

Zr-V2.5

(A2)

$\mathrm{v}=\mathrm{o}$
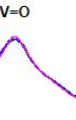

Zr-V5.0

(B2)
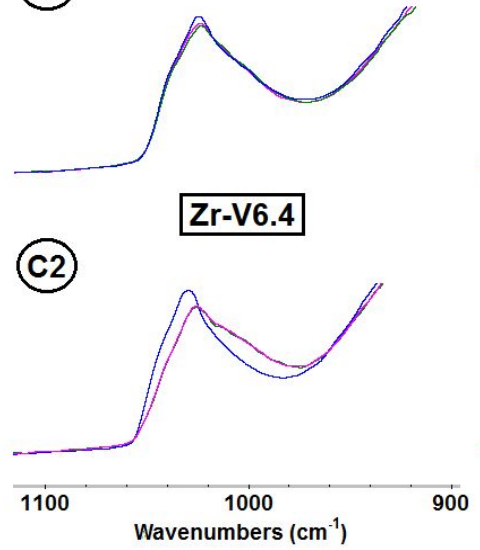

Post-reaction Spectra

Activation flow

after reaction flow

Raman Spectra (V=O, V-O-V and V-O-Zr Bonds)

(A3)

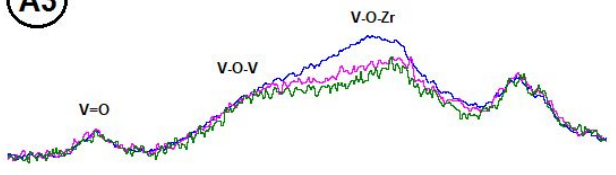

(B3)

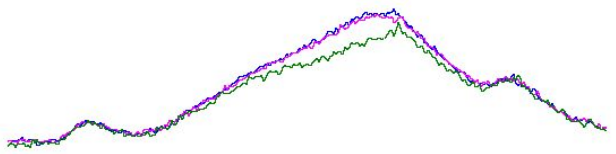

(C3)

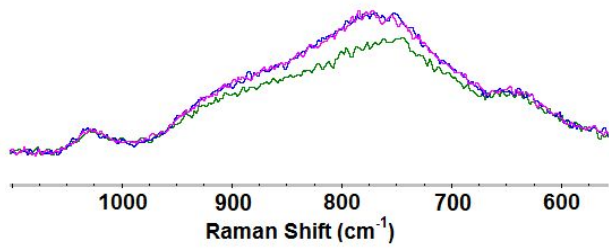

Figure S2. Operando FTIR (1 and 2) and Raman (3) spectra for (A) Zr-V2.5, (B) $\mathrm{Zr}-\mathrm{V} 5.0$ and (C) Zr-V6.4 at $200^{\circ} \mathrm{C}$. IR spectra shown at $1700-1100 \mathrm{~cm}^{-1}$ (1) were all subtracted with the reference spectrum of the sample under activation flow at the same temperature. Green traces represent experiments using ODH. Blue and pink traces represent experiments using activation flow before and after reaction, respectively. 


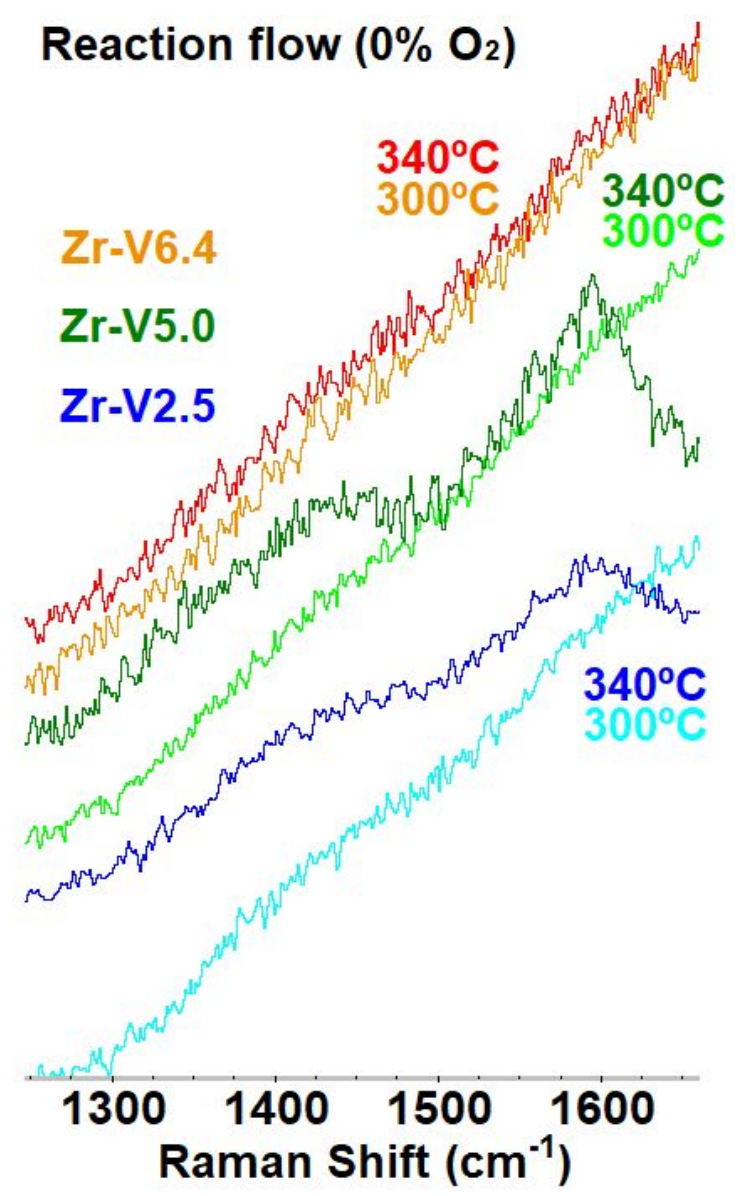

Figure S3. Operando Raman spectra for Zr-V2.5, Zr-V5.0 and Zr-V6.4 in the $1300-1600 \mathrm{~cm}^{-1}$ region during $\mathrm{DH}$ reaction (20\% propane in $\mathrm{He}$ ) at 300 and $340^{\circ} \mathrm{C}$.

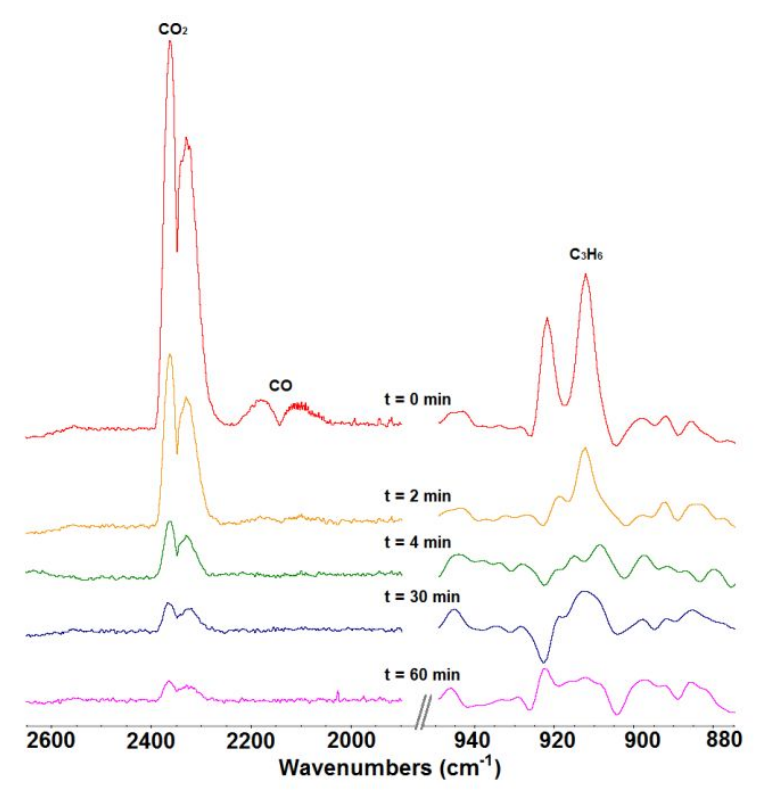

Figure S4. Evolution of the gas phase with time. FTIR spectra of Zr-V6.4 catalyst during $\mathrm{DH}$ reaction $\left(20 \% \mathrm{C}_{3} \mathrm{H}_{8}\right.$ in $\left.\mathrm{Ar}\right)$ at $340^{\circ} \mathrm{C}$. 


\section{References}

'Ternero-Hidalgo, J. J.; Torres-Liñán, J.; Guerrero-Pérez, M. O.; Rodríguez-Mirasol, J.; Cordero, T. Electrospun Vanadium Oxide Based Submicron Diameter Fiber Catalysts. Part I: Preparation Procedure and Propane ODH Application. Catal. Today 325, 131-143 (2019).

https://doi.org/10.1016/j.cattod.2018.10.073.

ii Ternero-Hidalgo, J. J.; Guerrero-Pérez, M. O.; Rodríguez-Mirasol, J.; Cordero, T. Electrospun Vanadium Oxide Based Submicron Diameter Fiber Catalysts. Part II: Effect of Chemical Formulation and Dopants.

Catal. Today 325, 144-150 (2019). https://doi.org/10.1016/j.cattod.2018.10.072.

iii Wuttke, S.; Bazin, P.; Vimont, A.; Serre, C.; Seo, Y.-K.; Hwang, Y. K.; Chang, J.-S.; Férey, G.; Daturi, M. Discovering the Active Sites for C3 Separation in MIL-100(Fe) by Using Operando IR Spectroscopy. Chem.

- Eur. J.18 (38), 11959-11967 (2012). https://doi.org/10.1002/chem.201201006. 